\title{
JNK-mediated microglial DICER degradation potentiates inflammatory responses to induce dopaminergic neuron loss
}

\author{
Qing Wang ${ }^{1+}$, Qian $\mathrm{He}^{1+}$, Yifei Chen ${ }^{1+}$, Wei Shao ${ }^{1}$, Chao Yuan ${ }^{1}$ and Yizheng Wang ${ }^{{ }^{*}}$
}

\begin{abstract}
Background: Amplified inflammation is important for the progression of Parkinson's disease (PD). However, how this enhanced inflammation is regulated remains largely unknown. Deletion of DICER leads to progressive dopamine neuronal loss and induces gliosis. We hypothesized that the homeostasis of microglial DICER would be responsible for the amplified inflammation in the mouse model of PD.

Methods: The microglia or C57BL/6 mice were treated or injected with I-methyl-4-phenyl-1,2,3,6-tetrahydropyridine (MPTP) or 1-methyl-4-phenylpyridinium $\left(\mathrm{MPP}^{+}\right)$, respectively, for the model establishment. Microglia and astrocytes sorted by fluorescence-activated cell sorter (FACS) were assayed by quantitative real-time PCR, Western blotting, immunoprecipitation, enzyme-linked immunosorbent assay (ELISA), immunohistofluorescence, and mass spectrometry.

Results: Microglial DICER was phosphorylated at serine 1456 by c-jun N-terminal kinase (JNK) and downregulated in response to 1-methyl-4-phenylpyridinium $\left(\mathrm{MPP}^{+}\right.$), a causative agent in PD. Inhibition of JNK phosphorylation of DICER at serine 1456 rescued the MPP ${ }^{+}$-induced DICER degradation, suppressed microglial inflammatory process, and prevented the loss of tyrosine hydroxylase-expressing neurons in the mouse MPTP model.
\end{abstract}

Conclusions: JNK-mediated microglial DICER degradation potentiates inflammation to induce dopaminergic neuronal loss. Thus, preventing microglial DICER degradation could be a novel strategy for controlling neuroinflammation in PD.

Keywords: DICER, Microglia, Inflammation, Degradation, Phosphorylation

\section{Background}

Parkinson's disease (PD) is the second prevalent neurodegenerative disease worldwide and is characterized by the loss of dopaminergic neurons in the substantia nigra pars compacta (SNpc) [1]. Studies have shown that the development and progression of $\mathrm{PD}$ are accompanied by the microglial inflammatory process [2]. Activated microglia and elevated pro-inflammatory factors, such as tumor necrosis factor-alpha (TNF- $\alpha$ ) and interleukin-1 beta (IL-1 $\beta$ ), have been found in the brains of PD patients and various PD models [3-5]. Lipopolysaccharide (LPS), a bacterial endotoxin, can activate microglial inflammatory responses to induce degeneration of nigrostriatal dopamine

\footnotetext{
* Correspondence: yzwang@ion.ac.cn

${ }^{\dagger}$ Qing Wang, Qian He and Yifei Chen contributed equally to this work.

${ }^{2}$ National Clinical Research Center for Aging and Medicine, Huashan Hospital, Fudan University, 12 Middle Wulumuqi Road, Shanghai 200040, People's

Republic of China

Full list of author information is available at the end of the article
}

neurons [6]. Anti-inflammatory agents, including naloxone and dexamethasone, can inhibit the activation of microglia and the production of pro-inflammatory cytokines to protect nigral dopaminergic neurons from degeneration $[7,8]$. These observations suggest that manipulation of microglial inflammatory responses can alter disease progression. Therefore, exploration of the regulatory mechanism underlying the microglial inflammatory responses will provide important information to PD pathogenesis and treatment.

The 1-methyl-4-phenyl-1,2,3,6-tetrahydropyridine (MPTP) metabolite $\mathrm{MPP}^{+}$is the causative agent in MPTP-induced parkinsonism in man and animals $[9,10]$. MPTP can produce Parkinsonian-like syndrome in animal models [11]. Astrocytes convert MPTP into 1-methyl-4-phenylpyridinium $\left(\mathrm{MPP}^{+}\right)$which is uptaken by neurons to cause oxidative stress, and neuronal death and debris released from damaged neurons activate microglia to promote inflammation, leading to more neuronal loss [12]. Therefore, activated microglia 
has a crucial role in propagating this vicious cycle of neuronal damage. A recent work shows that $\mathrm{MPP}^{+}$ can potentiate TNF- $\alpha$ production in microglia by downregulating miR-7116-5p, a microRNA targeting TNF- $\alpha$ [9]. The important roles of microglial microRNAs in regulating inflammatory responses are also shown in various kinds of diseases, including experimental autoimmune encephalomyelitis, intracerebral hemorrhage, and amyotrophic lateral sclerosis [1315]. These studies suggest that dysregulated microRNAs contribute to microglial inflammatory responses. As DICER, an RNase III family enzyme, is required for processing pre-miRNAs into mature microRNAs, exploring its potential involvement in microglial inflammatory responses might reveal novel insight into the molecular mechanism of inflammation in the PD brain.

Previous studies also show that artificial deletion of DICER in postmitotic dopamine neurons leads to progressive neuronal loss and that mice with DICER deletion in striatal neurons display ataxia, front and hind limb clasping, reduced brain size, and smaller neurons [16]. The DICER ablation in oligodendrocytes triggers gliosis and increases expression of inflammation markers [17]. The DICER deficit activates the NLRP3 inflammasome in the retinal pigmented epithelium [18]. However, whether DICER directly modulates microglial inflammatory responses in the MPTP model of PD remains unknown. In the current study, we report that $\mathrm{MPP}^{+}$induces c-jun $\mathrm{N}$-terminal kinase (JNK)-dependent and proteasome-mediated microglial DICER degradation to potentiate microglial inflammatory response and dopamine neuron loss. Our findings reveal a novel mechanism by which microglial inflammatory responses is controlled and potentiated in the PD models.

\section{Methods \\ Animals}

The C57BL/6 mice were from SLAK Laboratory Animal Shanghai, China. For the MPTP model, male wild-type C57BL/ 6 mice ( $8-10$ weeks, $n=6$ for each indicated group) were intraperitoneally injected with saline or 1-methyl-4-phenyl-1,2,3,6-tetrahydropyridine (MPTP) at $20 \mathrm{mg} / \mathrm{kg}$ for four times with $2 \mathrm{~h}$ intervals in 1 day as reported previously [19]. The successful establishment of the model was confirmed as about $60 \%$ loss of dopaminergic (DA) neurons in SNpc [12]. For the peptide blocking experiments, the fusion peptides at $250 \mathrm{mg} / \mathrm{kg}$ TAT-scramble or TAT-DICER (by China Peptides) were co-injected with MPTP or saline into the mice. The mice were sacrificed for Western blotting analysis or immunohistofluorescence, 3 or 7 days, respectively, after MPTP or saline injection.

\section{Microglia and astrocytes sorting from adult mouse ventral midbrain}

The ventral midbrain isolated from the brain of mice anesthetized was filtered through a 70- $\mu \mathrm{m}$ nylon cell strainer and digested with collagenase D $(0.05 \%$, Sigma, C5138) and DNase I (0.025 U/ml, Sigma) for $1 \mathrm{~h}$ at room temperature as reported previously [9]. After three washes with Hank's Balanced Salt Solution (HBSS, Invitrogen) to remove the enzymes, cells were resuspended and then stained with allophycocyanin (APC)-labeled cluster of differentiation 45 (CD45)/Alexa Fluor 488-labeled crossing cluster of differentiation molecule 11B (CD11b), APC-labeled glutamate aspartate transporter (GLAST) antibodies, or Alexa Fluor 488/APC-labeled isotype at $4{ }^{\circ} \mathrm{C}$ for $1 \mathrm{~h} . \mathrm{CD}_{11 \mathrm{~b}}{ }^{+} / \mathrm{CD} 45^{\text {low }}$ or $\mathrm{GLAST}^{+}$populations were then sorted by the flow cytometry (Cell Lab Quanta SC; Beckman Coulter, CA).

\section{Cell cultures, transfection, and drug treatment}

The microglia and astrocytes were obtained from the cerebral cortices of C57BL/6 mouse pups postnatal day $0-1$ as reported previously [9]. Briefly, the mouse cerebral cortices were isolated in cold phosphate-buffered saline (PBS), a water-based salt solution maintaining a constant $\mathrm{pH}$, osmolarity, and ion concentrations and then digested for $6 \mathrm{~min}$ at $37{ }^{\circ} \mathrm{C}$ in $0.25 \%$ trypsin followed by adding culture medium to terminate digestion. After filtered through the $70 \mu \mathrm{m}$ cell strainer, the suspensions were centrifuged at $1000 \mathrm{rpm}$ for $3 \mathrm{~min}$, and the pellets were then resuspended in Dulbecco's modified Eagle's medium (DMEM, Invitrogen) supplemented with $10 \%$ fetal bovine serum (FBS, Invitrogen) and antibiotics. Finally, the cells were cultured on $75 \mathrm{~cm}^{2}$ flasks. Seven to 9 days after seeding, the flasks were shaken at $200 \mathrm{rpm}$ for $2-3 \mathrm{~h}$. The cell suspension rich in microglia or the adhesive astrocytes was passed from the flasks into 12-well plates. The cells were used for experiments after 3-5 days. Primary cortical neurons were cultured from embryonic day 18 Sprague-Dawley rat brains and cultured in neurobasal supplemented with B27 and $0.5 \mathrm{mM}$ Glutamax for 912 days as reported previously [20]. The BV2 cells and HEK293 cells were cultured in DMEM supplemented with $10 \%$ FBS and antibiotics (penicillin and streptomycin) in the $5 \% \mathrm{CO} 2$ atmosphere at $37^{\circ} \mathrm{C}$.

All plasmids were transiently introduced into the cells using Lipofectamine 2000 (Invitrogen) following the manufacturer's protocol.

All drugs added to cells or injected into the mice were made fresh, and the corresponding solvent was used as a control.

\section{RNA isolation and quantitative real-time PCR}

The total RNA was extracted from microglia or BV2 cells using the Trizol reagent according to the manufacturer's 
instructions. A total of 1 or $5 \mu \mathrm{g}$ RNA from microglia or BV2 cells, respectively, were reverse-transcribed into cDNA using a reverse transcription system followed by quantitative real-time PCR (qRT-PCR) analysis. Target mRNA expression was quantified using the comparative Ct method ( $\Delta \Delta C t$ method) and normalized to the reference gene level expression. The PCR primer sequences for mRNA analysis were as follows:

DICER: forward 5'-GGTCCTTTCTTTGGACTGCC A-3', reverse 5' -GCGATGAACGTCTTCCCTGA-3' .

TNF- $\alpha$ : forward 5 '-CTATGGCCCAGACCCTCACA-3', reverse 5 '-TTGAGATCCATGCCGTTGG-3'.

IL-1ß: forward 5'-GCAACTGTTCCTGAACTCAAC T-3', reverse 5' -ATCTTTTGGGGTCCGTCAACT-3'.

COX-2: forward 5'-TGAGCAACTATTCCAAACCAG C-3', reverse 5' -GCACGTAGTCTTCGATCACTATC-3'.

iNOS: forward 5'-GTTCTCAGCCCAACAATACAA GA-3', reverse 5 ' -GTGGACGGGTCGATGTCAC- $3{ }^{\prime}$..

Actin: forward 5'-GGCTGTATTCCCCTCCATCG-3', reverse 5'-CCAGTTGGTAACAATGCCATGT-3'.

The identities of the PCR products were confirmed by sequencing analysis.

\section{MTT assay}

Microglia and BV2 cells were seeded on 12-well plates, and the medium was replaced with fresh DMEM or DMEM containing different concentration $\mathrm{MPP}^{+}$for $12 \mathrm{~h}$. The 3 (4,5-dimethylthiazol)-2-yl-2,5-diphenyl-tetrazolium bromide (MTT) solution $(1 \mathrm{mg} / \mathrm{ml}$ MTT in phosphate-buffered saline) was added to each well for $4 \mathrm{~h}$ at $37^{\circ} \mathrm{C}$. Then, the solution was replaced by solvent dimethyl sulfoxide (DMSO) to solubilize the eventually formed formazan crystals. Optical absorbance was calculated by measuring optic density values at $570 \mathrm{~nm}$.

\section{Western blotting}

Total proteins extracted from cells were separated by SDS/ 7-10\% PAGE gels and then transferred onto polyvinylidene difluoride (PVDF) membranes. After blocked with 5\% non-fat milk in PBS at room temperature for $1 \mathrm{~h}$, the membranes were incubated with the primary antibodies overnight at $4{ }^{\circ} \mathrm{C}$. The primary antibodies were used at the following concentrations: DICER (1:1000), Ago 2 (1:5000), Drosha (1:500), ubquitin (1:1000), phosphorylated JNK (1:1000), JNK (1:1000), Caspase-3 (1:1000), cleaved Caspase-3 (1:500), ERK1/2 (1:1000), phosphorylated ERK (1:500), spectrin (1:2000), HA (1:2000), phosphorylated p38 (1:300), p38 (1:1000), and phospho Serine (1:200). The next day, the membranes were washed and then incubated with the secondary polyclonal antibodies conjugated with horseradish peroxidase at room temperature for $2 \mathrm{~h}$. The protein bands were visualized with an ECL Western blotting substrate kit, and their densities were then quantified by densitometry analysis using ImageJ.

\section{Immunoprecipitation}

Briefly, microglia or BV2 cells were harvested and extracted in the lysis buffer containing $2 \mathrm{mM}$ EDTA or $20 \mathrm{mM}$ Tris- $\mathrm{HCl}$ (pH 8.0), $137 \mathrm{mM} \mathrm{NaCl}, 10 \%$ glycerol, $1 \%$ NP40, and 2 mM EDTA. The antibody DICER $(4 \mu \mathrm{g})$ was added into the lysates, and the mixtures were rotated at $4{ }^{\circ} \mathrm{C}$ overnight. Protein A/G beads were then added into the mixtures which were incubated for $2 \mathrm{~h}$ at room temperature. After washing three times with the lysis buffer, the immunoprecipitated proteins were analyzed using Western blotting.

\section{Enzyme-linked immunosorbent assay of TNF-a}

The TNF- $\alpha$ levels in the medium of microglia after LPS and/or $\mathrm{MPP}^{+}$were assessed by ELISA using a mouse TNF- $\alpha$ ELISA kit (BD Biosciences) according to the manufacturer's instructions.

\section{Immunohistofluorescence and image analysis}

The mice were perfused with saline followed by $4 \%$ paraformaldehyde (PFA) in $0.1 \mathrm{M}$ phosphate buffer (PB) 7 days after saline or MPTP injection. The isolated brains were postfixed in 4\% PFA and then dehydrated in $30 \%$ sucrose. Serial coronal sections were obtained at a thickness of $40 \mu \mathrm{M}$. Every fourth section of the entire slices was chosen to determine of the number of $\mathrm{TH}$-positive neurons in SNpc and analysis of the fluorescence intensity of GFAP and Ibal 1 . The sections were blocked with a normal donkey serum for $1 \mathrm{~h}$ and then were incubated with the primary antibodies (GFAP (1: 1000), Ibal 1 (1:1000), TH (1: 1000)) overnight at $4{ }^{\circ} \mathrm{C}$. After addition of the secondary antibodies, the sections were incubated for $2 \mathrm{~h}$ at room temperature followed by three washes with PBS. Images were obtained using Nikon Ti microscope (Nikon, Japan). TH counts by Image Pro Plus was performed through unbiased stereology and the fluorescence intensity of GFAP and Iba1 quantified by ImageJ was defined as the average intensity of glial scar area in MPTP-injected mice or the SNpc area in saline-injected mice.

\section{DICER phosphorylation analysis by mass spectrometry}

The phosphorylation of DICER was assayed by mass spectrometry as reported previously [21]. Briefly, immunoprecipitated samples from microglia and BV2 cells by the antibody against DICER or IgG were prepared. The precipitated proteins were separated by SDS/7\% PAGE gels and then Coomassie-stained. The interesting bands migrating at a molecular weight of $220 \mathrm{kDa}$ were cut for analysis. After destaining completely by destain solution (glacial acetic acid $(10 \%(v / v))$ and 30\% $(v / v)$ methanol), twice dehydrationby acetonitrile and the DICER bands were in-gel digested with trypsin overnight at $37{ }^{\circ} \mathrm{C}$. After centrifugation, the supernatant-containing tryptic 
peptides were acidified with $5 \%$ formic acid and separated on a C18 column, and peptides were analyzed by Thermo Q Exactive HF Mass Spectrometer.

\section{Plasmid construction}

The full-length sequences of mouse DICER from pCAGEN (Addgene, Plasmid \#50558) were subcloned into the pCIG vector. A hemagglutinin (HA) epitope sequence (YPYDVPDYA) was fused to the amino terminus of DICER, and the plasmid sequences were confirmed by sequencing analysis.

\section{Antibodies and drugs}

The following antibodies were used: TH (AB152) and spectrin (\#Mab 1622) from Millipore; Iba1 (\#01919741) from Wako; HA (H6908) and GFAP (G3893) from Sigma; Ago2 (sc-32877), Drosha (sc-33778), DICER (sc-30226), ubquitin (sc-8017), phosphorylated JNK (sc-6254), and JNK (sc-7345) from Santa Cruz Biotechnology; Caspase-3 (9662), cleaved Caspase-3 (\#9664 L), ERK1/2 (9102), phosphorylated ERK (9101S), phosphorylated p38 (9216S), and p38 (8690S) from Cell Signaling Technology; phospho Serine (37430) from Qiagen; CD11b-Alexa Fluor 488 (557672) and CD45-APC (559864) from BD Biosciences; and GLAST-APC (130-098-803) from MiltenyiBiotec.

The following drugs were used: lipopolysaccharide (LPS, L2630), $\mathrm{MPP}^{+}$(D048), MPTP (M0898), calpeptin (C8999) or MDL28170 (M6690), N-carbobenzoxyl-L-leucyl-L-leucyl-norvalinal (MG115, C6706), and lactacystin (L6785) from Sigma; U0126 (HY-12031), SP600125 (HY-12041), and SB203580 (HY-10256A) from Medchemexpress; and Z-DEVD-FMK (S7312) from Selleck.

\section{Statistics}

Data were mean + SEM. All experiments were done independently at least three times. All statistical analyses were conducted using Office Excel 2007 and GraphPad Prism 5. Two-tailed Student's $t$ tests were used for comparisons between two groups and one-way ANOVA with Newman-Keuls post hoc test for more than two groups. Differences were considered to be significant when a $p$ value is less than 0.05 .

\section{Results}

Microglial DICER protein is specifically downregulated in the mouse MPTP model

We first examined whether DICER expression is affected in microglia, neurons, or astrocytes in the mouse MPTP model. Exposure of the primary cultured microglia to $\mathrm{MPP}^{+}$led to a great reduction in DICER protein levels (Fig. 1a). In contrast, the levels of other proteins important for microRNA processing, including Argonaute 2 (Ago2), the core component of RNA-induced silencing complex (RISC), and Drosha, a nuclear RNase III, remained unchanged in microglia treated with $\mathrm{MPP}^{+}$(Fig. 1b). Further, DICER expression was not affected in the primary cultured mouse neurons or astrocytes in response to various concentrations of $\mathrm{MPP}^{+}$(Fig. 1c). Moreover, there was no difference in microglia viability in the absence or presence of $\mathrm{MPP}^{+}$for $12 \mathrm{~h}$ as assayed by the MTT test (Additional file 1a). These results provided the initial evidence to suggest that DICER expression is specifically suppressed in microglia by $\mathrm{MPP}^{+}$.

We then examined the effects of $\mathrm{MPP}^{+}$on DICER expression in the BV2 cells, a murine microglial cell line that is commonly used for investigation of microglia function [22]. Similarly, decreased expression of DICER by $\mathrm{MPP}^{+}$ was evident, whereas that of Ago2 or Drosha was not observed (Fig. 1d). The MTT test showed that $\mathrm{MPP}^{+}$did not affect the viability of BV2 cells (Additional file $1 \mathrm{~b}$ ). We then examined microglial DICER levels in the mouse MPTP model. We sorted microglia by fluorescence-activated cell sorting (FACS) and studied DICER expression in the microglia. We found that DICER expression was greatly suppressed in the cluster of differentiation molecule $11 \mathrm{~B}$ (CD11b)-positive and CD45-low microglia in ventral mesencephalon (VM) of mice 3 days after MPTP injection. In contrast, the expression of Ago2 and Drosha was not changed (Fig. 1e). To clarify whether DICER expression in astrocytes is changed, we isolated glutamate aspartate transporter (GLAST, the astrocyte marker)-positive cells by FACS and found that there was no difference in DICER levels between saline- and MPTP-injected mice (Fig. 1f). Altogether, these results suggest that DICER proteins in microglia are specifically downregulated in the mouse MPTP model.

\section{Proteasome mediates microglial DICER downregulation induced by MPP ${ }^{+}$}

We next investigated whether the reduction in DICER protein level is due to its mRNA reduction. We measured DICER mRNA levels by quantitative real-time PCR (qRT-PCR) and observed that DICER mRNA levels were not changed in microglia (Fig. 2a) and BV2 cells (Fig. 2b) following $\mathrm{MPP}^{+}$engagement. Similarly, DICER mRNA levels in FACS-isolated microglia from mice injected with MPTP were not changed compared with those from mice injected with saline (Fig. 2c). These results suggest that the reduction in DICER protein levels might be attributed to post-translational regulation. It has been reported that DICER can be degraded by proteases (calpain-1 and caspase-3) [23-25] or proteasome [26, 27]. We explored whether DICER reduction is due to either proteases or proteasome. As illustrated in Fig. 2d and Additional file 2a, the cleaved fragment of $\alpha$-spectrin, one of the well-defined calpain substrates [28], was not observed in microglia or BV2 cells incubated with $\mathrm{MPP}^{+}$for different times, suggesting that calpain is not activated, and hence, it is 


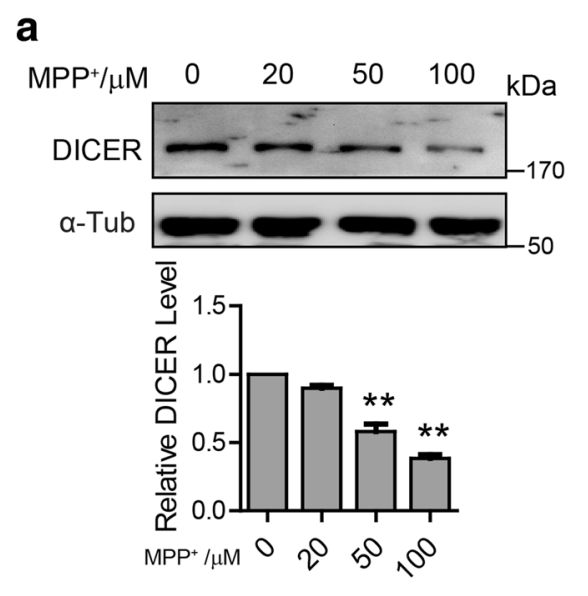

C
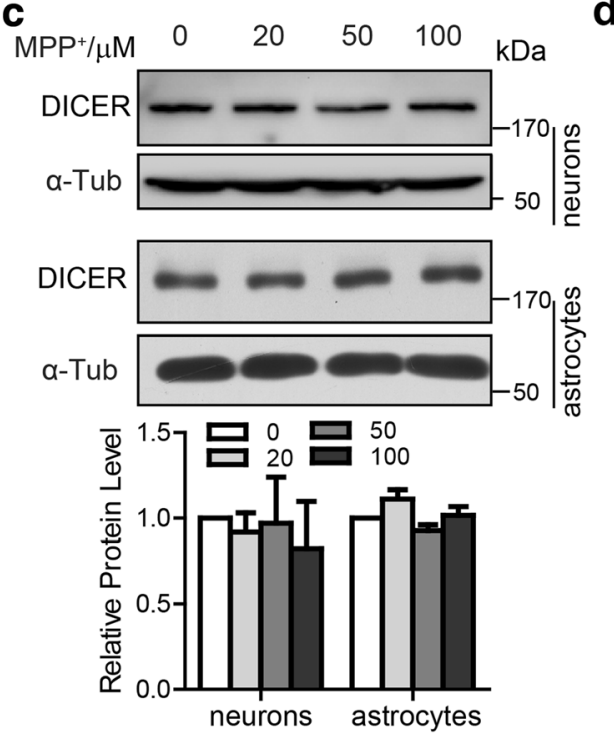

e

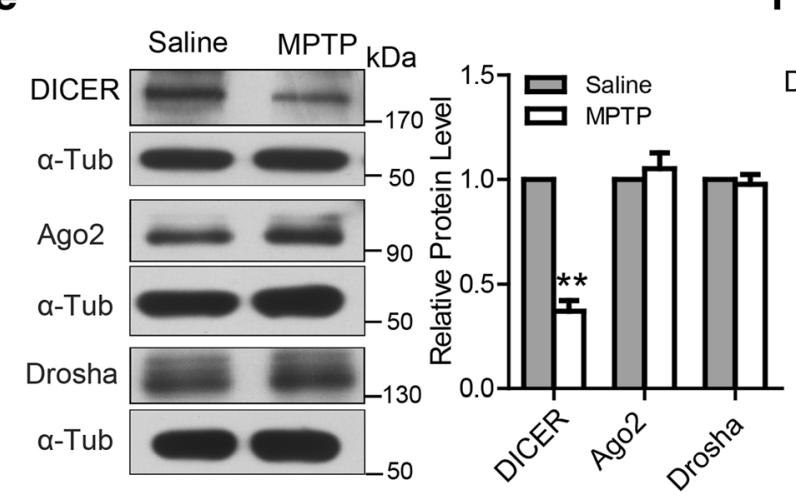

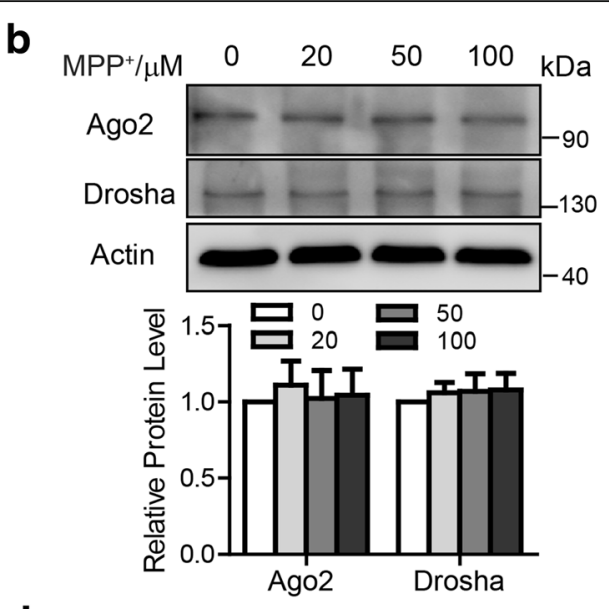

d
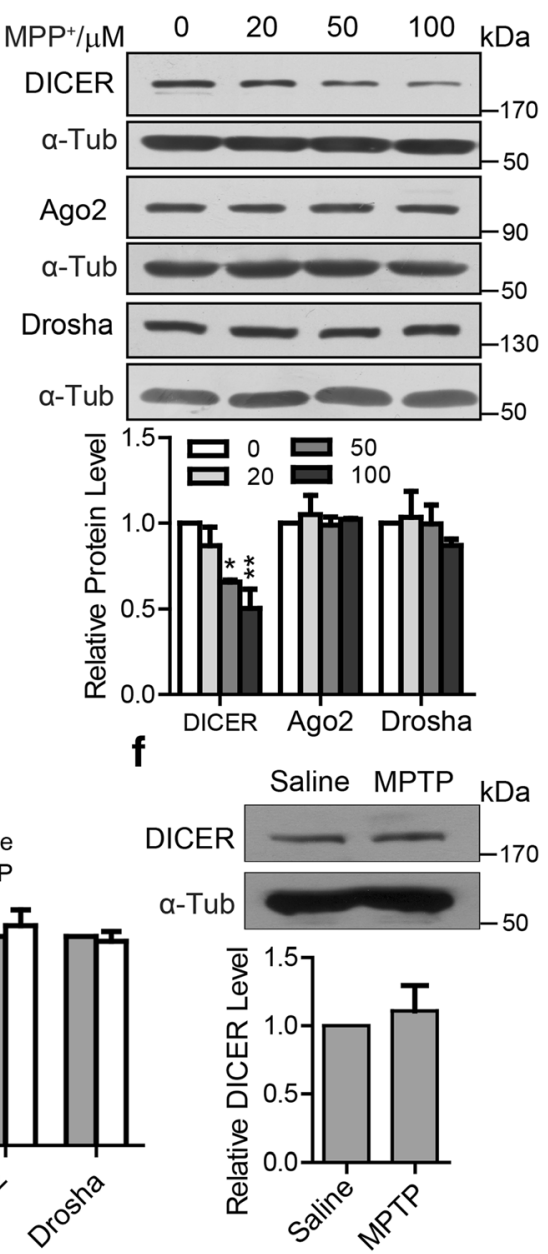

Fig. 1 (See legend on next page.) 


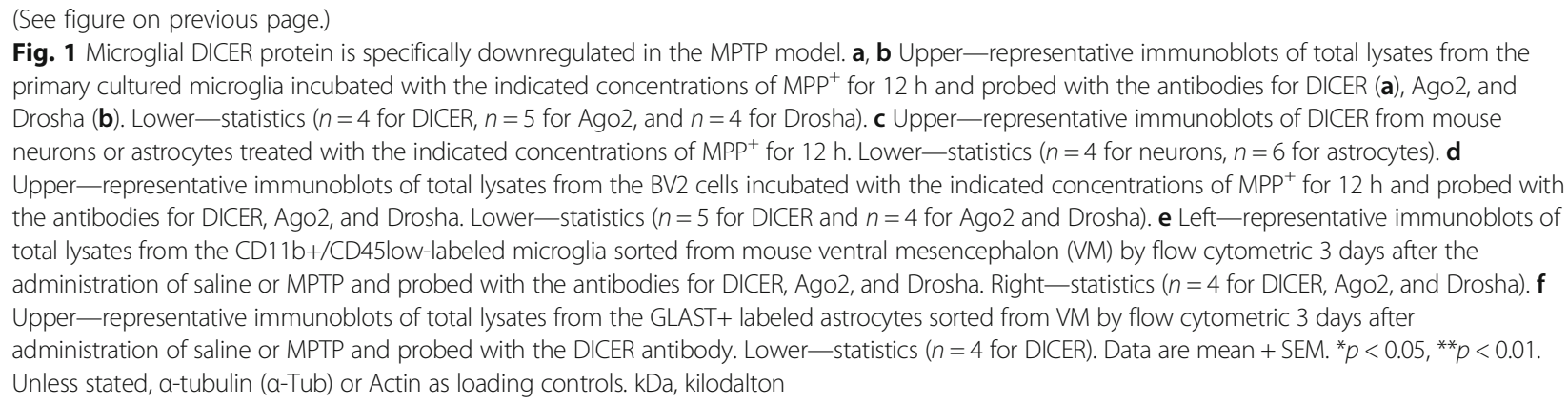

unlikely that calpain is involved in DICER reduction caused by $\mathrm{MPP}^{+}$. This notion was further supported by the findings that DICER reduction was not rescued by calpeptin or MDL28170, the calpain inhibitors (Fig. 2e and Additional file 2d), although they greatly inhibited glutamate-induced the cleavage of $\alpha$-spectrin into the characteristic fragments in neurons (Additional file $2 b$ ). Additionally, caspase-3 activation was not observed in microglia incubated with $\mathrm{MPP}^{+}$(Fig. 2f and Additional file 2c). Moreover, the addition of Z-DEVD-FMK (DEVD), an agent known to inhibit caspase-3, to the microglia did not affect $\mathrm{MPP}^{+}$-induced DICER reduction (Fig. 2g). However, $\mathrm{MPP}^{+}$-induced DICER reduction was markedly prevented when the microglia were incubated with lactacystin or $N$-carbobenzoxyl-L-leucyl-L-leucyl-norvalinal (MG115), agents known as proteasome inhibitors (Fig. 2h, i and Additional file 2e, f). These results suggest that proteasome participated in $\mathrm{MPP}^{+}$-induced DICER degradation. This assumption was further supported by the findings that DICER ubiquitination was greatly increased when microglia were incubated with $\mathrm{MPP}^{+}$(Fig. 2j and Additional file $2 \mathrm{~g}$ ). Taken together, these observations suggest that $\mathrm{MPP}^{+}$-induced DICER reduction in microglia is due to its degradation mediated by proteasome.

\section{JNK is responsible for microglial DICER degradation induced by MPP ${ }^{+}$}

It has been reported that phosphorylation of a protein plays a role in its proteasomal degradation [29]. Treatment of microglia with $\mathrm{MPP}^{+}$greatly increased the activities of mitogen-activated protein (MAP) kinases, including the extracellular signal-regulated kinases (ERKs, $\mathrm{p} 42$, and $\mathrm{p} 44$ ), the c-Jun N-terminal kinases (JNKs), and the p38 MAP kinases as evidenced by their respective phosphorylations. The ERK, JNK, and p38 MAPK were activated as early as $5 \mathrm{~min}$ after $\mathrm{MPP}^{+}$engagement both in microglia (Fig. $3 \mathrm{a}-\mathrm{c}$ ) and BV2 cells (Fig. 3d-f). To assess the role of MAPKs in $\mathrm{MPP}^{+}$-induced DICER degradation, we then examined the effects of inhibition of these kinases on DICER degradation. Incubating microglia with U0126, SP600125, or SB203580, agents known as specific inhibitors to ERK, JNK, or p38 MAP kinase, respectively, markedly suppressed the phosphorylation of these kinases (Additional file $3 \mathrm{a}-\mathrm{c}$ ). The $\mathrm{MPP}^{+}$-induced DICER degradation was reversed when the microglia (Fig. 3h) or BV2 cells (Fig. 3j) were incubated with SP600125. In contrast, U0126 and SB203580 did not affect $\mathrm{MPP}^{+}$-induced DICER degradation (Fig. 3g-j). In addition, SP600125 eliminated $\mathrm{MPP}^{+}$-induced DICER ubiquitination (Fig. 3k). Together, these results provided the initial evidence to suggest that JNK might participate in $\mathrm{MPP}^{+}$-induced DICER degradation.

Serine 1456 in microglial DICER is phosphorylated by JNK We next examined whether JNK has a role in DICER phosphorylation and degradation. We transfected HEK293 cells with JNK and hemagglutinin (HA) epitope-tagged DICER expression constructs and immunoprecipitated whole cell lysates with HA antibody followed by immunoblotting using the antibody against phosphorylated serine. As shown in Fig. 4a, a phosphoserine signal at DICER position was detected, whereas no signal was observed without JNK transfection, suggesting that serine phosphorylation of DICER is JNK-dependent. Exposure of microglia to $\mathrm{MPP}^{+}$ caused an increase in phosphorylated serine signal migrating at DICER position (Fig. 4b). Similarly, elevation of serine phosphorylation of DICER was found in BV2 cells by $\mathrm{MPP}^{+}$(Fig. 4c). Moreover, $\mathrm{MPP}^{+}$-induced serine phosphorylation of DICER was suppressed by SP600125 (Fig. 4d). Taken together, these results suggest that $\mathrm{MPP}^{+}$activates JNK to phosphorylate DICER.

To clearly show that DICER is indeed phosphorylated by JNK, we used liquid chromatography-tandem mass spectrometry to further identify the phosphorylation site(s) of DICER in microglia exposed to $\mathrm{MPP}^{+}$. Mass spectrometry (MS) analysis of the DICER from $\mathrm{MPP}^{+}$-treated microglia (Fig. 4e) and BV2 cells (Additional file 4a) revealed that mouse DICER contained a phosphorylation site at serine 1456 (Ser 1456). This particular serine is highly conserved between human, mouse, and rat (Fig. 4f), suggesting that it is an important phosphorylation site for DICER. The bioinformatics 
a

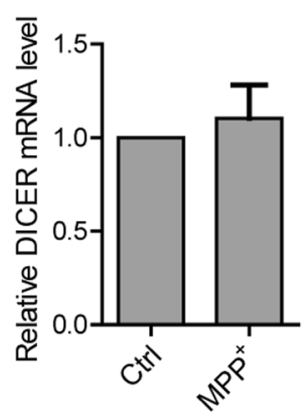

d

$\mathrm{MPP}^{+} \mathrm{OH} \quad 4 \mathrm{H} \quad 8 \mathrm{H} \quad 12 \mathrm{H}_{\mathrm{kDa}}$

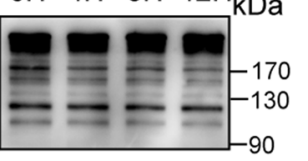

Actin

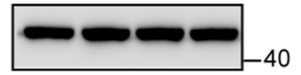

f

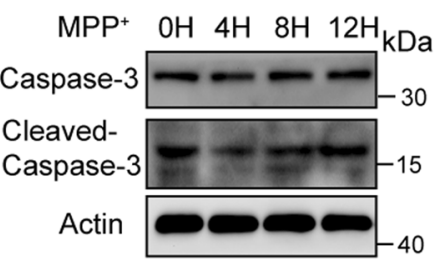

b

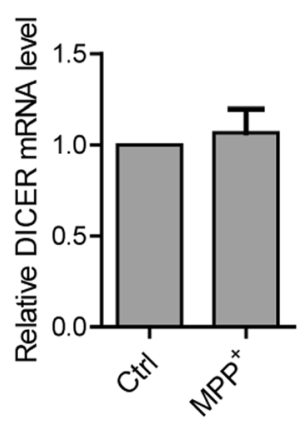

e

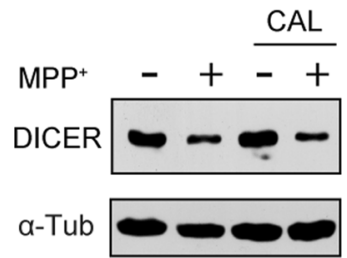

g

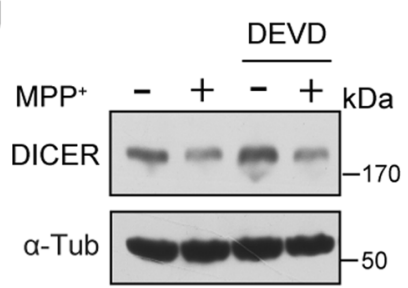

i

h
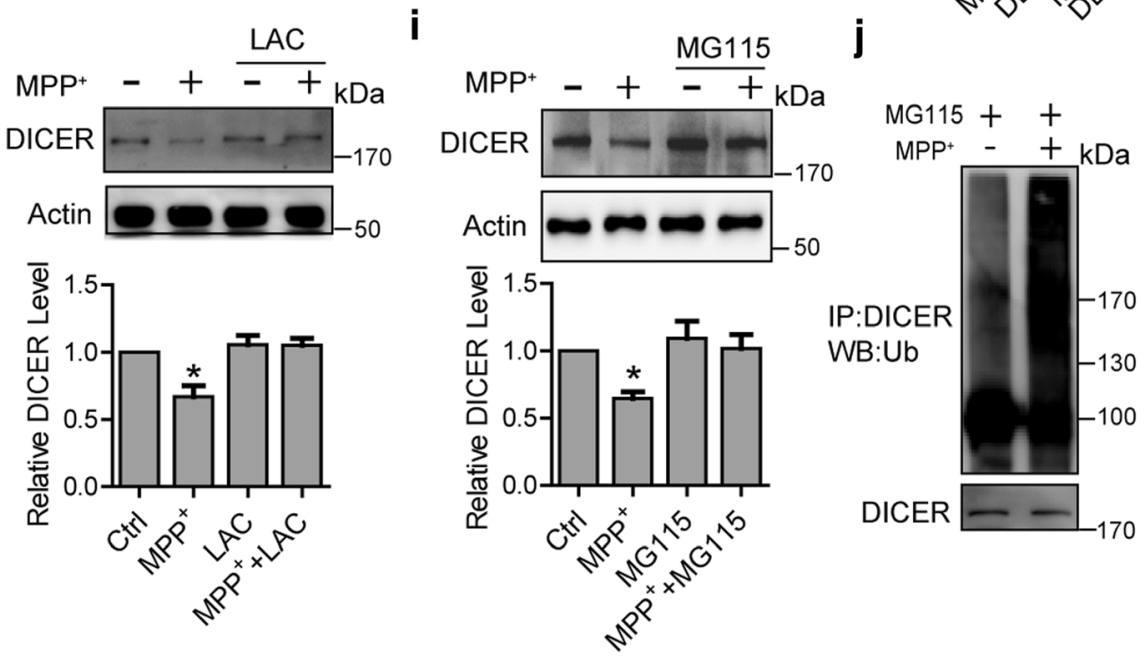

Fig. 2 Inhibition of proteasome suppresses microglial DICER downregulation induced by MPP ${ }^{+}$. a, b Quantitative PCR analysis of DICER mRNA levels in microglia $(\mathbf{a}, n=4)$ and BV2 cells $(\mathbf{b}, n=4)$ treated with $\mathrm{MPP}^{+}(100 \mu \mathrm{M})$ for $12 \mathrm{~h}$. $\mathbf{c}$ Quantitative PCR examination of DICER mRNA levels in microglia sorted from VM of mice after saline or MPTP injection $(n=4)$. $\mathbf{d}$ Representative immunoblots of total lysates from microglia treated with MPP ${ }^{+}$for the indicated times with the antibody against a-spectrin. e Representative immunoblots of total lysates from BV2 cells incubated with MPP ${ }^{+}$together with the calpeptin (CAL, $10 \mu \mathrm{M})$ or MDL28170 (MDL, $60 \mu \mathrm{M})$ for $12 \mathrm{~h}$ and probed with the indicated antibodies. $\mathbf{f}$ Representative immunoblots of total lysates from microglia treated with $\mathrm{MPP}^{+}$for the indicated times using the antibodies against caspase-3 or cleaved caspase-3. $\mathbf{g}$ Left-representative immunoblots of total lysates from BV2 cells incubated MPP ${ }^{+}$with/without Ac-DEVD-CHO (DEVD, $\left.10 \mu \mathrm{M}\right)$ and probed with the indicated antibodies. Right—statistics $(n=4)$. h, i Upper—representative immunoblots of total lysates from microglia treated with MPP ${ }^{+}$with/without lactacystin $(L A C, 1 \mu M$, h) or N-carbobenzoxyl-L-leucyl-L-leucyl-norvalinal (MG115, $1 \mu \mathrm{M}$, i) for $12 \mathrm{~h}$ and probed with the indicated antibodies. Lower-statistics ( $n=3$ for $L A C$ and $n=4$ for MG115). $\mathbf{j}$ Representative immunoblots of immunoprecipitates of total lysates from microglia treated with/without MPP ${ }^{+}$in the presence

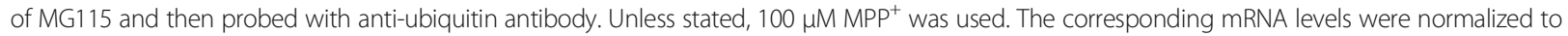
actin levels. Data are mean + SEM. ${ }^{*} p<0.05,{ }^{* *} p<0.01,{ }^{* * *} p<0.001$ 


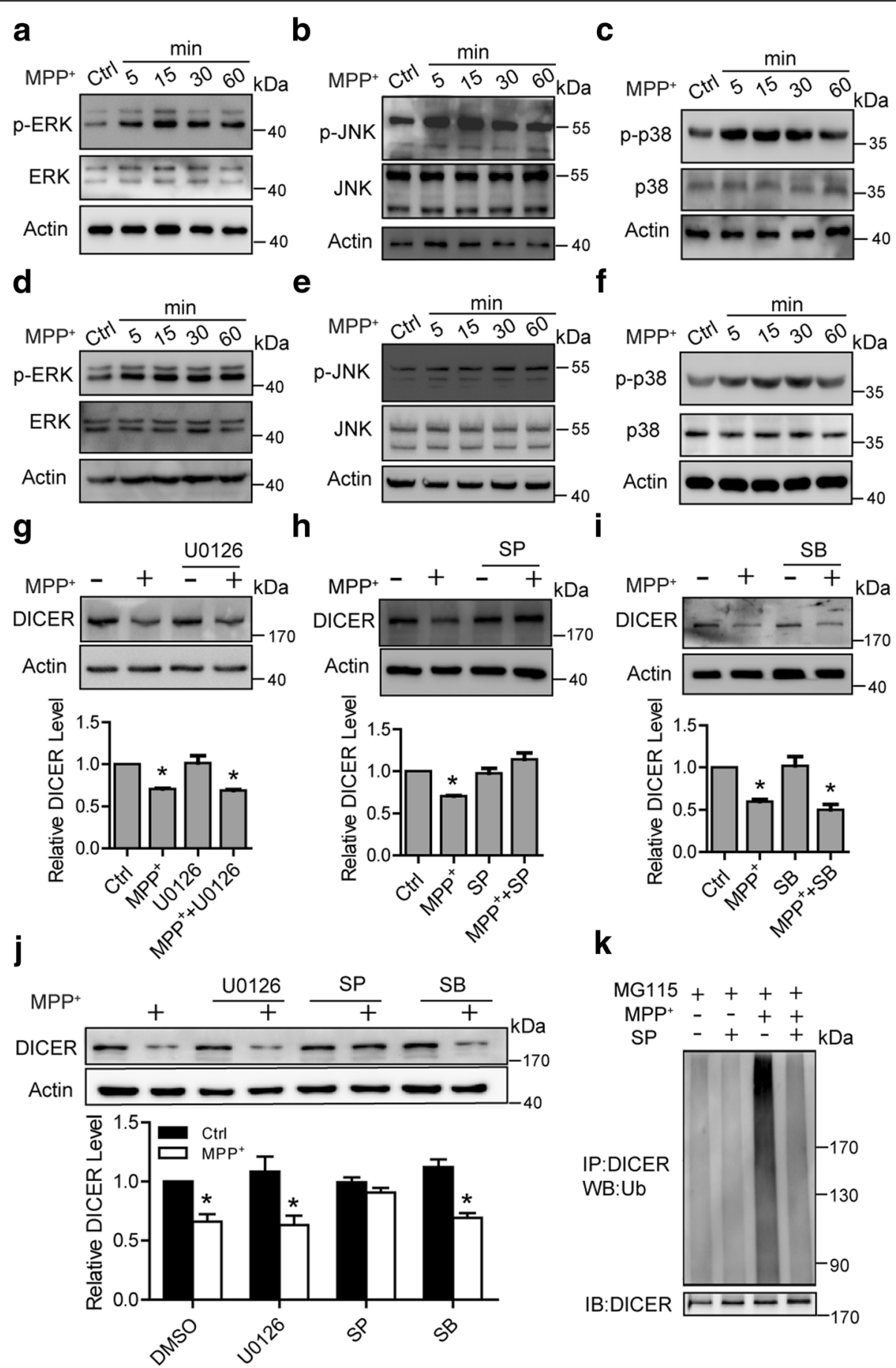

Fig. 3 Inhibition of JNK suppresses microglial DICER degradation induced by MPP ${ }^{+}$. a-f Representative immunoblots of total lysates from microglia $(\mathbf{a}-\mathbf{c})$ and BV2 cells $(\mathbf{d}-\mathbf{f})$ exposed to MPP ${ }^{+}$for the indicated times and probed with the antibodies for p-ERK and ERK (a, d), for p-JNK and JNK (b, e), and for p-p38 and p38 (c, $\mathbf{f}) . \mathbf{g}-\mathbf{j}$ Representative immunoblots of total lysates from microglia $(\mathbf{g}-\mathbf{i})$ and BV2 cells $(\mathbf{j})$ treated with $\mathrm{MPP}^{+}$or/and $\mathrm{U} 0126(\mathbf{g}, \mathbf{j}, 10 \mu \mathrm{M})$, SP600125 (SP, $\left.10 \mu \mathrm{M}\right)(\mathbf{h}, \mathbf{j})$, and SB203580 (SB, $\left.10 \mu \mathrm{M}\right)(\mathbf{i}, \mathbf{j})$ using the antibodies against DICER. Lower-statistics $(\mathbf{g}-\mathbf{i} ; n=3$ for $\mathbf{g}, n=4$ for $\mathbf{h}$, and $n=3$ for $\mathbf{i}$, and $n=3$ for $\mathbf{j})$. $\mathbf{k}$ Upper-representative immunoblots of immunoprecipitates from total lysates of BV2 cells pretreated SP600125 for $2 \mathrm{~h}$ and then incubated with MG115 with/without MPP ${ }^{+}$and immunoblotted with anti-ubiquitin antibody. Lower-immunoblots of the DICER precipitates. Data are mean + SEM. ${ }^{*} p<0.05$ 

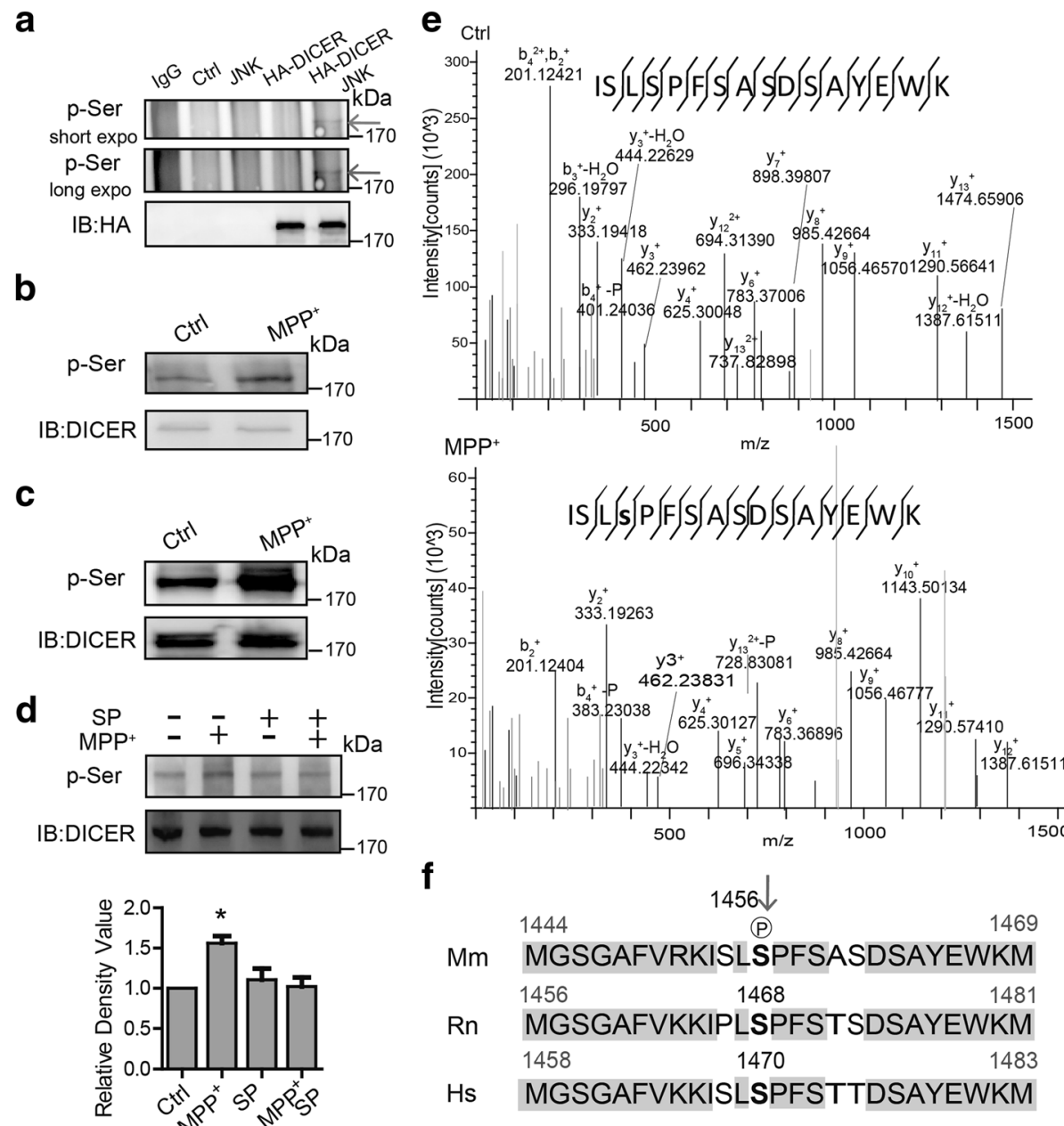

Fig. 4 Microglial DICER is phosphorylated at serine 1456 by JNK. a Representative immunoblots of immunoprecipitates from the total lysates of HEK293 cells transfected with control (Ctrl), JNK, or/and HA-tagged DICER (HA-DICER) constructs and probed with anti-phospho Ser antibody. Lower-immunoblots of the precipitates with anti-HA antibody. b, c Representative immunoblots of immunoprecipitates of DICER from total lysates of microglia (b) and BV2 cells (c) exposed to $\mathrm{MPP}^{+}$for $30 \mathrm{~min}$ and probed with the anti-phospho Ser antibody. d Upper-representative immunoblots of immunoprecipitates from total lysates of BV2 cells preincubated with SP600125 for $2 \mathrm{~h}$ then with MPP for 30 min and probed with the anti-phospho Ser antibody. Lower-statistics $(n=3)$. Data are shown as mean + SEM. ${ }^{*} p<0.05$. e Mass spectrometry (MS) analysis of the DICER immunoprecipitated from the microglia incubated in the absence (upper, Ctrl) or presence (lower, MPP ${ }^{+}$) of MPP ${ }^{+}$for 30 min. The phosphorylated serine residue was shown in lowercase bold letter. $\mathbf{f}$ Multiple sequence alignment of DICER containing the conserved serine residue in Mus musculus (Mm) (1444-1469), Rattus norvegicus (Rn) (1456-1481), and Homo sapiens (Hs) (1458-1483). Residues are colored based on percentage identity

prediction using Group-based Prediction software 3.0, a tool used to predict of kinase-specific phosphorylation sites [30], suggested that serine 1456 is a new candidate JNK phosphorylation site (Additional file 4b). Sequence analysis revealed that the Ser 1456 is followed by a proline, consistent with the notion that DICER is phosphorylated by JNK, a well-known proline-directed kinase. The MS analysis further revealed that $\mathrm{MPP}^{+}$ induced Ser 1456 phosphorylation, and the phosphorylation was abolished by SP600125 in microglia (Additional file 4c). Altogether, these results suggest that JNK indeed mediates DICER serine 1456 phosphorylation.

\section{Inhibiting DICER Ser 1456 phosphorylation prevents the} $M^{M P{ }^{+}}$-induced DICER degradation

To provide clear evidence that Ser 1456 phosphorylation is indeed important for $\mathrm{MPP}^{+}$-induced DICER degradation, we designed a synthetic peptide comprising amino acid sequence 1448-1465 spanning the JNK phosphorylation site of mouse DICER, fused it to the protein transduction domain of the HIV-1 transactivator protein (TAT) and named it as TAT-DICER (Fig. 5a). Initial experiments were performed to investigate if the TAT-DICER could indeed affect Ser 1456 phosphorylation of DICER. As shown in Fig. 5b, TAT-DICER did inhibit Ser 1456 
a

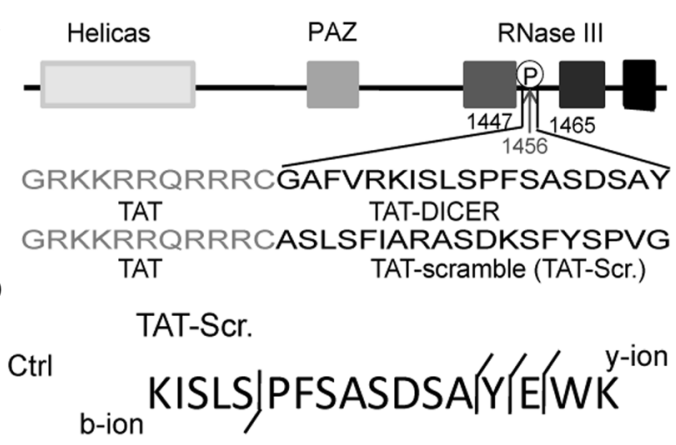

$\mathrm{MPP}^{+}$TAT-Scr.

b-ion

KISL/s/PFSAISDISAIY/E/WK

Ctrl

TAT-DICER

b-ion

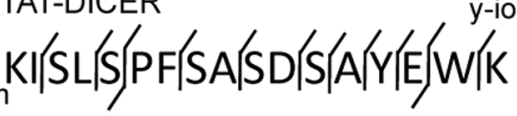

MPP $^{+}$TAT-DICER

$\mathrm{K}$

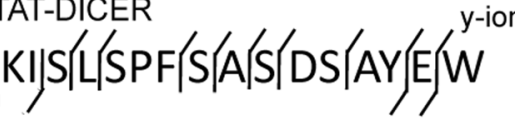

C

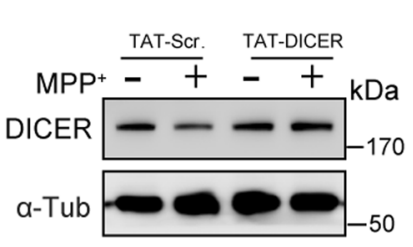

d
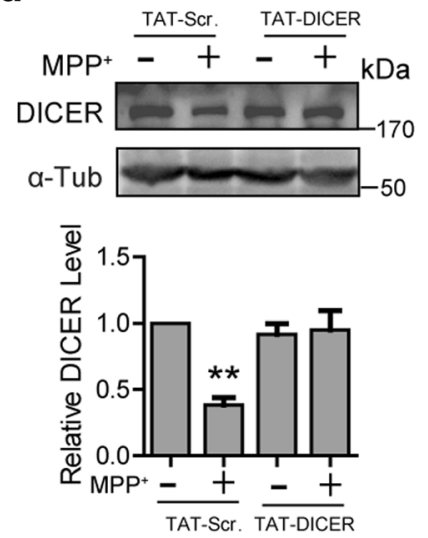

e

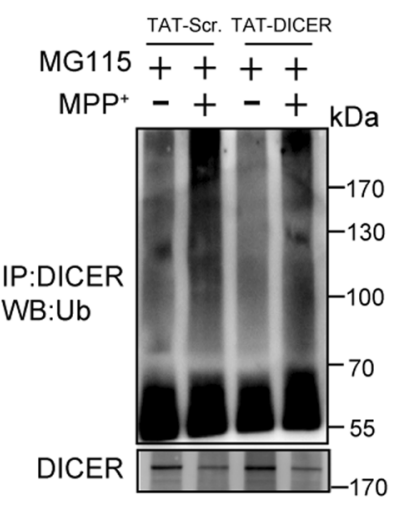

Fig. 5 TAT-DICER prevents DICER degradation. a Schematic diagram of the TAT-DICER and TAT-scramble (TAT-Scr.) peptides. The letters with the light background indicate the 11 amino acid residues of the HIV transactivator protein (TAT). TAT was fused to the $\mathrm{N}$ terminus of the 19 amino acids containing Ser 1456 in mouse DICER. b MS analysis of the DICER immunoprecipitated from microglia pre-incubated with TAT-Scr. or TAT-DICER for $24 \mathrm{~h}$ and then with $\mathrm{MPP}^{+}$for $30 \mathrm{~min}$. The phosphorylated serine residue was shown in lowercase bold letter. (c, d) Upper-representative immunoblots of total cell lysates of microglia (c) or BV2 cells (d) incubated with TAT-Scr. or TAT-DICER for $24 \mathrm{~h}$ and then with MPP for $12 \mathrm{~h}$. Lower-statistics $(n=4$ for $\mathbf{c}$ and $\mathbf{d}$ ). e Representative immunoblots of the immunoprecipitates of total cell lysates of BV2 cells incubated with TAT-Scr. or TAT-DICER for $24 \mathrm{~h}$ and then with $\mathrm{MPP}^{+}$for another $8 \mathrm{~h}$ in the presence of MG115 and detected with anti-ubiquitin antibody. Data are mean + SEM. ${ }^{* *} p<0.001$

phosphorylation in microglia induced by $\mathrm{MPP}^{+}$. Moreover, the TAT-DICER also suppressed DICER degradation in microglia induced by $\mathrm{MPP}^{+}$(Fig. 5c). Similar results were also obtained in BV2 cells (Fig. 5d). Consistently, TAT-DICER greatly inhibited $\mathrm{MPP}^{+}$-induced DICER ubiquitination (Fig. 5e). Collectively, these results suggest that JNK-mediated Ser 1456 phosphorylation plays a crucial role in DICER degradation.

\section{Microglial DICER degradation by $\mathrm{MPP}^{+}$potentiates its inflammatory responses}

Since microglia is the central immunocompetent cells in the brain [31], we investigated whether DICER degradation plays a role in microglial inflammatory responses. We evaluated the microglial activation by measuring the expression of pro-inflammatory mediators, including TNF- $\alpha$,interleukin 1 beta (IL-1 $\beta$ ), inducible nitric oxide synthase (iNOS) and cyclooxygenase-2 (COX-2) (Fig. 6a). The qRT-PCR analysis showed that mRNA levels of these factors were not affected by $\mathrm{MPP}^{+}$, suggesting that $\mathrm{MPP}^{+}$-regulated DICER degradation does not initiate the microglial inflammatory responses (Fig. 6b-e). Nevertheless, when microglial cells were incubated with lipopolysaccharide (LPS), an agent well known to activate microglia, the expression of these factors was increased (Fig. 6b-e). Moreover, the increased expression of these factors was greatly amplified when the microglia were pre-exposed to $\mathrm{MPP}^{+}$(Fig. 6b-e). In addition, TNF- $\alpha$ protein level measured by enzyme-linked immunosorbent assay (ELISA) was also markedly potentiated (Fig. 6f). These results point to a possibility that DICER degradation caused by $\mathrm{MPP}^{+}$leads to the hyper-microglial inflammatory responses. 

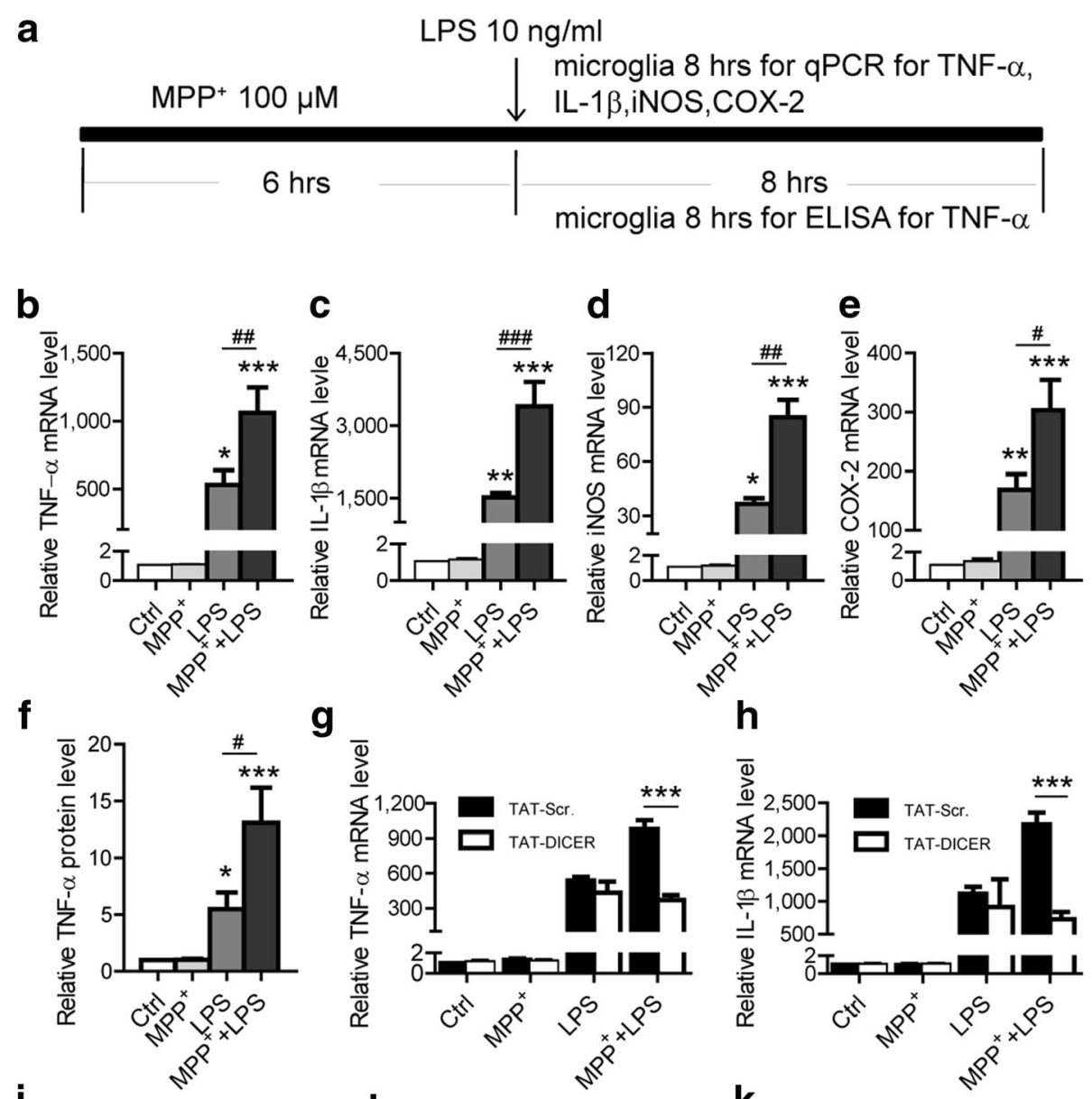

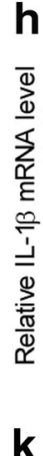
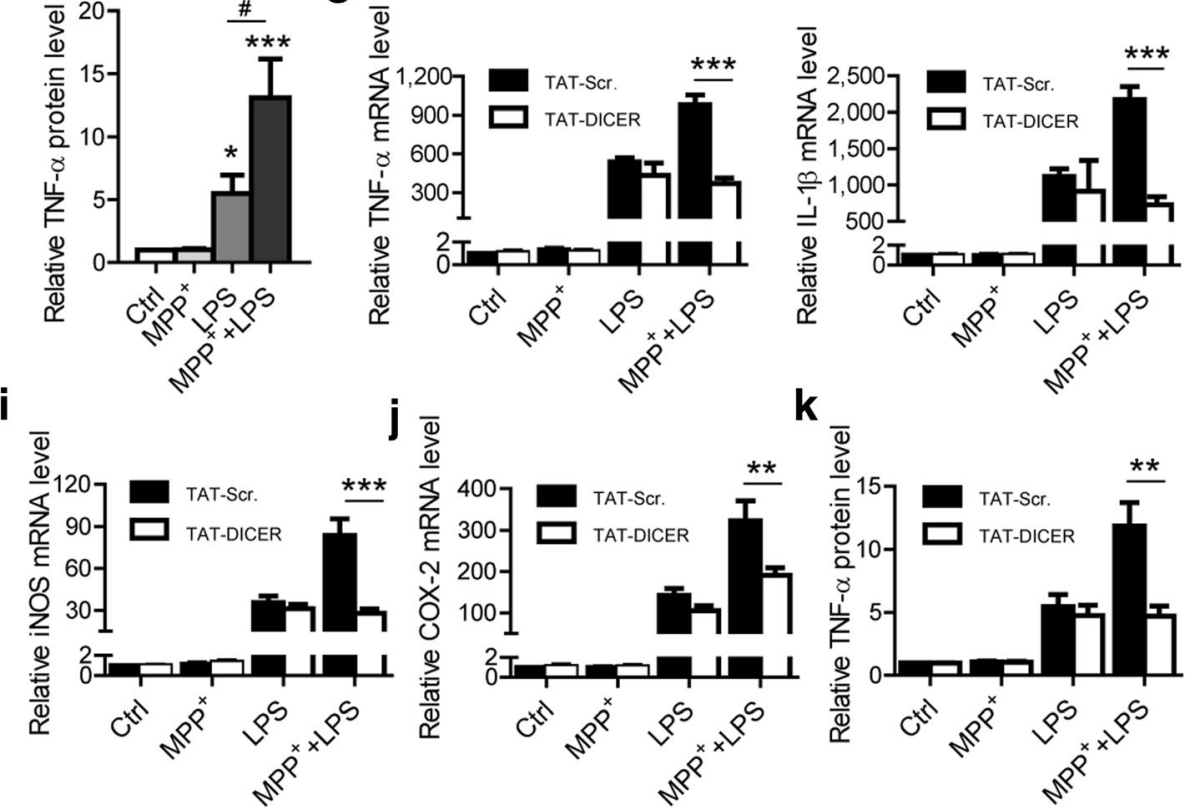

Fig. 6 Degradation of DICER in microglia potentiates inflammatory responses. a The experimental diagram for $\mathbf{b}-\mathbf{k}$. Microglia were incubated with TAT-DICER or TAT- TAT-Scr. for $24 \mathrm{~h}$ and then with MPP ${ }^{+}$and/or for the indicated time. $\mathbf{b}-\mathbf{e}$ Quantitative PCR analysis of TNF-a $(\mathbf{b}, n=4)$, IL-1 $\beta(\mathbf{c}, n=3)$, iNOS $(\mathbf{d}, n=4)$, and COX-2 $(\mathbf{e}, n=4)$ mRNA levels in microglia treated with MPP ${ }^{+}$or/and LPS. $\mathbf{f}$ ELISA examination of protein levels of TNF-a in the supernatant of microglia treated with MPP ${ }^{+}$or/and LPS. $\mathbf{g}-\mathbf{j}$ Quantitative PCR analysis of TNF-a $(\mathbf{g}, n=7)$, IL-1 $(\mathbf{h})$, iNOS (i), and COX-2 $(\mathbf{j}, n=8)$ mRNA levels in microglia incubated with TAT-Scr. or TAT-DICER for $24 \mathrm{~h}$ and then with MPP ${ }^{+}$or/and LPS. $\mathbf{k}$ ELISA examination of TNF-a protein levels in the supernatant of microglia incubated with TAT-Scr. or TAT-DICER for $24 \mathrm{~h}$ then with MPP ${ }^{+}$or/and LPS $(n=6)$. Data are mean + SEM. Comparisons between groups were performed with one-way ANOVA with Tukey's post hoc test (b-f) or two-way ANOVA with Bonferroni post hoc test $(\mathbf{g}-\mathbf{k}) .{ }^{*} p<0.05,{ }^{* *} p<0.01,{ }^{* * *} p<0.001 .{ }^{\#} p<0.05,{ }^{\# \#} p<0.01,{ }^{\# \# \#} p<0.001$

To directly explore whether the reduction in DICER indeed has a role in microglial responses to LPS, we examined the effects of TAT-DICER on the production of these factors induced by LPS in the presence or absence of $\mathrm{MPP}^{+}$. The TAT-DICER did not affect the production of TNF- $\alpha$, IL- $1 \beta$, iNOS, and COX- 2 induced by LPS
(Fig. $6 \mathrm{~g}-\mathrm{j}$ ). In contrast, the production of these factors potentiated by $\mathrm{MPP}^{+}$was eliminated when microglia were incubated with TAT-DICER, but not with TAT-scramble (Fig. 6g-j). Additionally, exposure to TAT-DICER, but not to TAT-scramble, abolished $\mathrm{MPP}^{+}$-potentiated TNF- $\alpha$ protein production (Fig. 6k). Thus, DICER reduction 
induced by $\mathrm{MPP}^{+}$greatly contributes to the amplification in microglial inflammatory responses.

\section{Inhibiting microglial DICER degradation limits its hyper- inflammatory responses and rescues TH-positive neuron loss in the mouse MPTP model}

The results above suggest that DICER in microglia is degraded in the MPTP models and that its degradation leads to the exaggerated inflammatory responses in cultured microglia. To show whether DICER degradation has a role in the regulation of microglial inflammatory responses in the mouse MPTP model, we injected TAT-DICER or TAT-scramble into the mice and examined their effects on DICER reduction and inflammation. Western blot analysis of the total lysates of the microglia isolated by FACS from the ventral mesencephalon revealed that the TAT-DICER remarkably inhibited DICER degradation in the mice injected with MPTP (Fig. 7a). Next, we detected microglial or astrocytic activation as evidenced by ionized calcium-binding adapter molecule 1 (Ibal1) or glial fibrillary acidic protein (GFAP) immunohistofluorescence staining, respectively. Neither TAT-scramble nor TAT-DICER itself affected Ibal1 and GFAP expression. In contrast, the expression of Iball and GFAP was increased in mice injected with MPTP, and the increased expression of Ibal1 and GFAP was markedly inhibited by TAT-DICER, but not by TAT-scramble (Fig. 7b, d).

To determine whether TAT-DICER-inhibited glial activation has a role in nigral dopaminergic neuron loss in the mouse MPTP model, we counted tyrosine hydroxylase ( $\mathrm{TH}$, a marker for dopamine neurons)-positive neuron number in the mice. The numbers of $\mathrm{TH}$-positive neurons were greatly reduced in the mouse MPTP model and TAT-DICER markedly prevented the reduction in the number of TH-positive neurons caused by MPTP (Fig. 7c, d). Taken together, these results suggest that microglial DICER degradation in the mouse MPTP model greatly contributes to glial hyperactivation and TH-positive neuron loss.

\section{Discussion}

In this study, we report JNK-mediated degradation of DICER by neurotoxin $\mathrm{MPP}^{+}$and its crucial role in microglial hyper-inflammatory responses to cause dopamine (DA) neuron loss. Several lines of experimental results support this conclusion. First, microglial DICER was specifically degraded via the proteasomal pathway in response to $\mathrm{MPP}^{+}$. Second, $\mathrm{MPP}^{+}$caused JNK activation and inhibition of JNK activities stopped microglial DICER degradation. Third, JNK phosphorylated DICER at serine 1456. Fourth, inhibition of microglial DICER Ser 1456 phosphorylation prevented its degradation as well as its hyper-inflammatory responses. Last, inhibition of microglial DICER degradation limited its hyperactivation and reduced DA neuron loss in the mouse MPTP model. Since specific and progressive dopaminergic neuron loss is one of the key characteristics of the PD pathology, the microglial DICER degradation suggests a particular role of this specific regulation of DICER in the pathogenesis of PD. Thus, preventing microglial DICER degradation may be a new strategy to curb microglial hyper-inflammatory responses and DA neuron loss in PD (Fig. 7e).

The DICER has important roles in diverse biological processes, including chromatin structure remodeling, immune responses, and stem-cell maintenance and differentiation [32-35]. Therefore, DICER expression level should be tightly controlled. At the post-translational level, DICER is glycosylated to maintain its intracellular level and proper folding [36]. Smoking-induced DICER SUMOylation in lung macrophages results in abnormal profiles of microRNA expression [37]. Phosphorylation of DICER on Ser 1705 and Ser 1833 by ERK triggers its nuclear localization to coordinate oocyte-to-embryo transition in the development of Caenorhabditis elegans [38]. Here, we showed that JNK phosphorylation of microglial DICER at Ser 1456 induced by neurotoxin $\mathrm{MPP}^{+}$promotes its degradation. Injection of TAT-DICER, a cell-permeable peptide with the ability to pass the blood-brain barrier [39-41], prevented DICER phosphorylation and degradation. Thus, DICER is phosphorylated by different kinases to function in different biological processes. It should be pointed out that although JNK activation is found in neurons, astrocytes $[42,43]$, and microglia, DICER degradation induced by $\mathrm{MPP}^{+}$was observed only in microglia. It is thus possible that an E3 ligase specific for DICER is present only in microglia. This assumption is consistent with the findings that inhibition of DICER phosphorylation by TAT-DICER suppressed its ubiquitination and degradation in microglia induced by $\mathrm{MPP}^{+}$.

Previous studies reported that a genetic deletion of DICER in forebrain excitatory neurons or oligodendrocytes leads to astrogliosis and microgliosis [17, 44], while little is known about the role of DICER in microglia. One important finding of the current study is that microglial DICER degradation potentiated its inflammatory responses. A recent study showed that DICER knock-out in adult microglia leads to hyperactivation of these cells after LPS challenges [45]. Therefore, it is likely that DICER can affect the inflammation in cell autonomous and non-cell autonomous manners. In this context, inhibiting DICER reduction to curb inflammation is a novel approach to specifically affect the inflammatory process. It remains unclear how DICER affects microglial inflammatory responses. Our recent work reports that miR-7116-5p, a microRNA targeting TNF- $\alpha$, is downregulated by $\mathrm{MPP}^{+}$and potentiates TNF- $\alpha$ production in microglia [9]. Therefore, changes in 
a

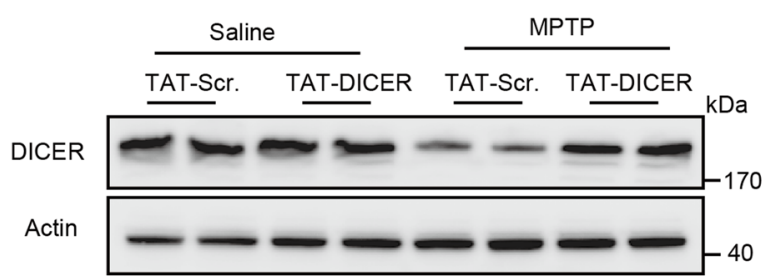

b
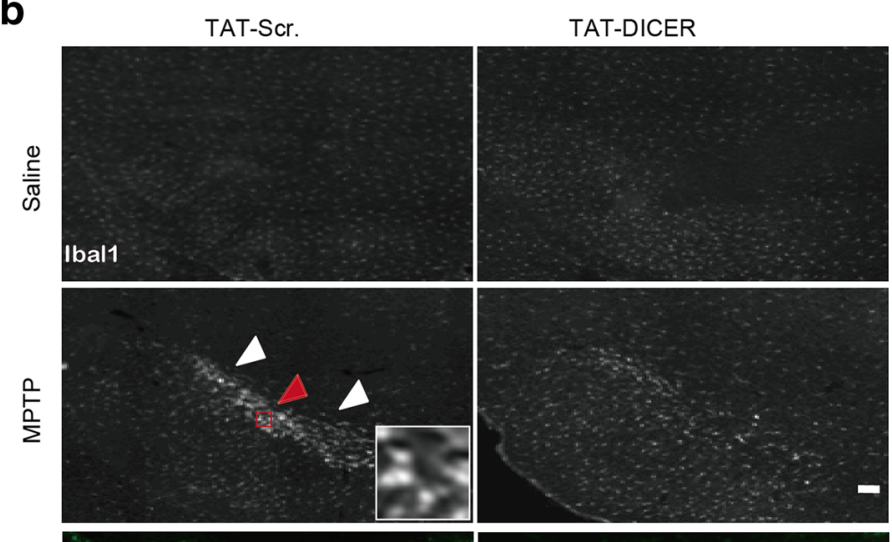

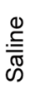
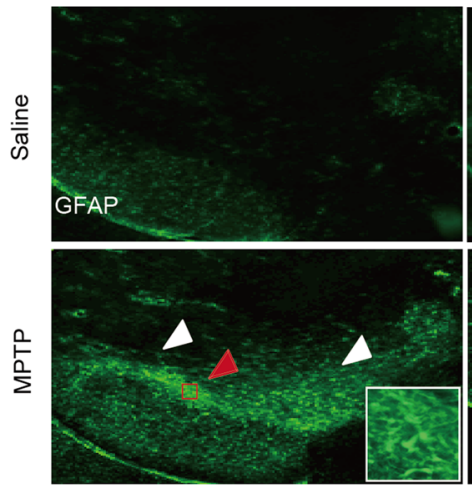

C

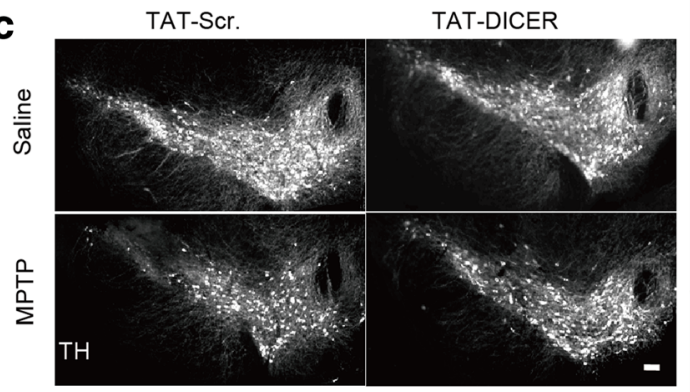

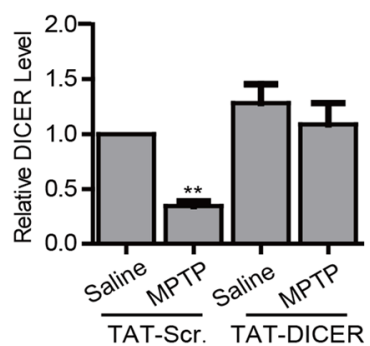

d TAT-SCr.
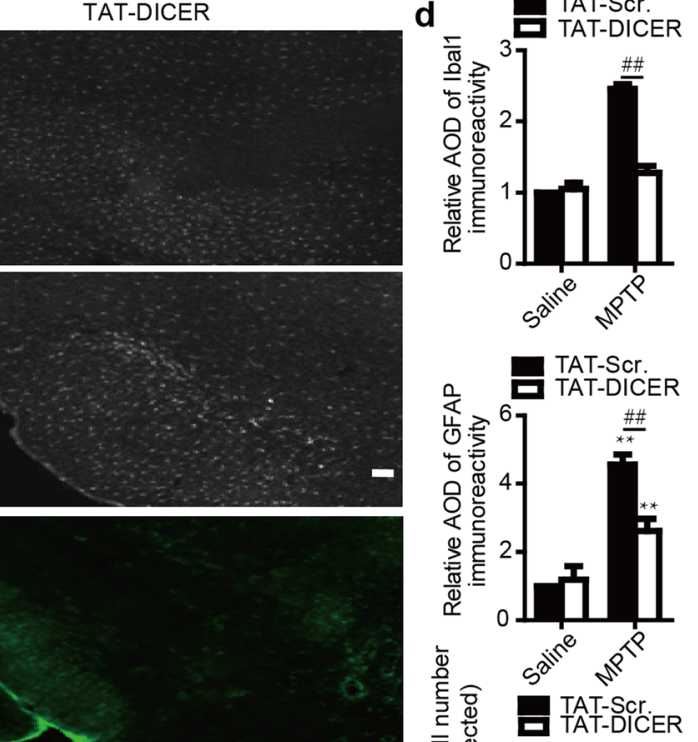

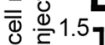

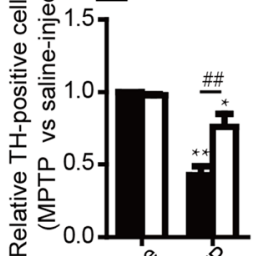

$3^{30^{2}} 3$

e
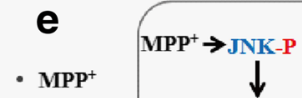

K-P

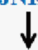

DICER-P

$\downarrow$

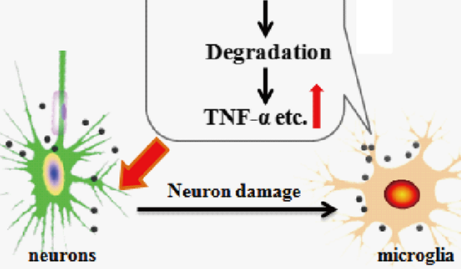

Fig. 7 Inhibition of microglial DICER degradation suppresses inflammatory responses and reduces tyrosine hydroxylase-positive neuron loss in the mouse MPTP model. a Left—representative immunoblots of total lysates of microglia sorted from VM of mice 3 days after saline or MPTP injection together with TAT-Scr. or TAT-DICER and probed with the antibody against DICER. Right—statistics $(n=5)$. $\mathbf{b}$, $\mathbf{c}$ Representative images of

immunohistofluorescence staining with antibodies against Iba1 (top two, b) and GFAP (bottom two, b) in the ventral tegmental area and tyrosine hydroxylase (c) in the SNpc of mice 7 days after the administration of saline or MPTP with TAT-Scr. or TAT-DICER. In $\mathbf{b}$, the images in the small squares magnified from the area indicated by the red arrows. Scale bar, $200 \mu \mathrm{M}$. AOD, average optical densities. $\mathbf{d}$ Statistics for $\mathbf{b}$ (top two, $n=6$ for Ibal 1 and $n=5$ for GFAP) and $\mathbf{c}($ bottom, $n=4)$. e Schematic diagram of the working model. Microglial DICER phosphorylation and degradation by MPP ${ }^{+}$ amplified the inflammation caused by damaged neurons, leading to enhanced DA neuron loss. Data are mean + SEM. ${ }^{*} p<0.05,{ }^{* *} p<0.001$, ${ }^{\# \#} p<0.01$ 
microRNA expression likely play an important role in DICER deficit-induced inflammation. Additionally, DICER deficit in the retinal pigmented epithelium induces accumulation of Alu RNA to activate NLRP3 inflammasome $[18,46]$. It is not clear whether microglial hyperactivation responses induced by DICER degradation are due to the long non-coding RNA Alu-dependent mechanism.

From the lessons of the current clinical trials of Alzheimer's disease [47], it is believed that there is no beneficial effect to inhibit inflammation in late-stage patients who have been with obvious symptoms, and it is therefore necessary to select a right time to curb the amplified inflammation. A key finding of the current study is that DICER is degraded at the early time in the pathogenic process in the mouse MPTP model. Consistently, preventing DICER degradation at this stage significantly suppressed glial activation and improved DA neuron survival. Additionally, pre-treating mice with eicosanoyl-5-hydroxytryptamide, which had a direct anti-inflammatory effect, for 4 weeks showed a robust protection for dopaminergic neurons following MPTP challenge [48], and co-administration anti-inflammatory drug MDG548 injected 15 min before MPTP prevented DA neuron loss [49]. Moreover, the use of ibuprofen, a compound known to inhibit inflammation, is associated with lowering PD risk [50]. Therefore, the inhibition of inflammation by the early inhibition of DICER degradation would be a promising strategy to prevent neurodegeneration.

\section{Conclusions}

Microglial DICER is phosphorylated by JNK to induce its degradation, potentiate microglial inflammatory processes, and enhance DA neuron damage. These observations revealed an unknown regulatory mechanism of microglial DICER and its role in promoting microglial hyperactivation of inflammation in the mouse MPTP model. The demonstration of JNK-mediated DICER degradation in the brain will further expand our understanding of the amplification of microglial inflammation.

\section{Additional files}

\footnotetext{
Additional file 1: Related to Fig. 1 ( $a$ and b) The viability of microglia ( $a$ $n=3)$ and BV2 cells $(b, n=3)$ determined by MTT assay $12 \mathrm{~h}$ after MPP ${ }^{+}$ treatment. Data shown as mean + SEM. (PNG 17 kb)

Additional file 2: Related to Fig. 2 (a) Representative immunoblots of total lysates of BV2 cells treated with $100 \mu \mathrm{M} \mathrm{MPP}^{+}$for the indicated times with the antibody against a-spectrin. (b) Representative immunoblots of total lysates of primary cultured neurons treated with $50 \mu \mathrm{M}$ glutamate (Glu) or/and calpeptin (CAL) or MDL28170 (MDL) for $4 \mathrm{~h}$ with the antibody against a-spectrin. (c) Representative immunoblots of total lysates of BV2 cells treated with MPP ${ }^{+}$for the indicated times with the antibody against caspase-3 and cleaved caspase-3. (d) Statistics of DICER in Fig. 2e. (e) Upper, representative immunoblots of total lysates from BV2 cells treated with $100 \mu \mathrm{M} \mathrm{MPP}^{+}$with/without LAC $(1 \mu \mathrm{M})$ (e) or MG115 $(1 \mu \mathrm{M})(\mathrm{f})$ for $12 \mathrm{~h}$ and detected with the indicated antibodies. Lower:
}

statistics. (g) Representative immunoblots of immunoprecipitates for total lysates of BV2 cells treated with MG115 with or without MPP ${ }^{+}$and then probed with anti-ubiquitin antibody. Data are shown as mean + SEM. ${ }^{*} p$ $<0.05,{ }^{* *} p<0.01,{ }^{* * *} p<0.001$. a-tubulin (a-Tub), a loading control. kDa, kilodalton. (PNG $512 \mathrm{~kb}$ )

Additional file 3: Related to Fig. 3 (a-c) Representative immunoblots of total lysates of BV2 cells treated with U0126 (a), SP (b), and SB (c) with indicated antibodies. $a$-tubulin (a-Tub), a loading control. kDa, kilodalton. (PNG $54 \mathrm{~kb}$ )

Additional file 4: Related to Fig. 4 (a) Mass spectrometry (MS) analysis of the DICER immunoprecipitated from BV2 cells treated with MPP ${ }^{+}$for $30 \mathrm{~min}$. The phosphorylated serine residue as revealed by MS is shown in lowercase bold letter. (b) Table representing a list of JNK phosphorylation sites of DICER predict by GPS3.0. (c) MS analysis of the DICER immunoprecipitated from microglia pre-incubated with or without SP for $2 \mathrm{~h}$ and then with $\mathrm{MPP}^{+}$for $30 \mathrm{~min}$. The phosphorylated serine residue as revealed by MS is shown in lowercase bold letter. (PNG $289 \mathrm{~kb}$ )

\section{Abbreviations}

Ago2: Argonaute 2; APC: Allophycocyanin; CD11b: Crossing cluster of differentiation molecule 11B; CD45: Cluster of differentiation 45; COX2: Cyclooxygenase-2; DEVD: Z-DEVD-FMK; ELISA: Enzyme-linked immunosorbent assay; ERK: Extracellular signal-regulated kinase; FACS: Fluorescence-activated cell sorter; FBS: Fetal bovine serum; GFAP: Glial fibrillary acidic protein; GLAST: Glutamate aspartate transporter; Ibal1: Ionized calcium-binding adapter molecule 1; IL-1B: Interleukin-1 beta; iNOS: Inducible nitric oxide synthase; JNK: c-jun N-terminal kinase; LPS: Lipopolysaccharide; MAP: Mitogen-activated protein; MG115: N-carbobenzoxyl-L-leucyl-L-leucylnorvalinal; MPP': 1-Methyl-4-phenylpyridinium; MPTP: I-Methyl-4-phenyl1,2,3,6-tetrahydropyridine; MS: Mass spectrometry; MTT: 3 4,5-Dimethylthiazol2-yl-2,5-diphenyl-tetrazolium bromide; PBS: Phosphate-buffered saline; PD: Parkinson's disease; PFA: Paraformaldehyde; PVDF: Polyvinylidene difluoride; qRT-PCR: Quantitative real-time PCR; SNc: Substantia nigra compacta; TH: Tyrosine hydroxylase; TNF-a: Tumor necrosis factor-alpha; VM: Ventral mesencephalon

\section{Acknowledgements}

The authors thank L. Wu and X. Li for the cell cultures and MF. Liu, RG. Hu, ZG. Luo, and JW. Zhou for the discussion.

\section{Funding}

The work is supported by grants from the Ministry of Science and Technology of China (2015ZX09102005) and Beijing Municipal Science and Technology Commission (Z151100003915120).

\section{Availability of data and materials}

All data supporting the conclusions of this study are presented in the manuscript.

\section{Authors' contributions}

$\mathrm{QW}, \mathrm{QH}$, and YFC performed the experiments and wrote the manuscript. WS corrected the manuscript. CY did the imaging. YZW supervised the study and wrote the manuscript. All authors read and approved the final manuscript.

\section{Ethics approval}

All animal studies were performed with the approval by the Institutional Animal Care and Use Committee of the Institute of Neuroscience, Shanghai, China.

\section{Competing interests}

The authors declare that they have no competing interests.

\section{Publisher's Note}

Springer Nature remains neutral with regard to jurisdictional claims in published maps and institutional affiliations. 


\section{Author details}

'Center of Cognition and Brain Science, Beijing Institute of Medical Sciences, Beijing 100000, People's Republic of China. ${ }^{2}$ National Clinical Research Center for Aging and Medicine, Huashan Hospital, Fudan University, 12 Middle Wulumuqi Road, Shanghai 200040, People's Republic of China.

Received: 24 January 2018 Accepted: 29 May 2018

Published online: 15 June 2018

\section{References}

1. Braak H, Del Tredici K, Rub U, de Vos RAl, Steur ENHJ, Braak E. Staging of brain pathology related to sporadic Parkinson's disease. Neurobiol Aging. 2003:24:197-211.

2. Kim YS, Joh TH. Microglia, major player in the brain inflammation: their roles in the pathogenesis of Parkinson's disease. Exp Mol Med. 2006:38:333-47.

3. Hirsch EC, Vyas S, Hunot S. Neuroinflammation in Parkinson's disease. Parkinsonism Relat Disord. 2012;18:S210-2.

4. Liu B, Hong JS. Role of microglia in inflammation-mediated neurodegenerative diseases: mechanisms and strategies for therapeutic intervention. J Pharmacol Exp Ther. 2003;304:1-7.

5. Long-Smith CM, Sullivan AM, Nolan YM. The influence of microglia on the pathogenesis of Parkinson's disease. Prog Neurobiol. 2009:89:277-87.

6. Dutta G, Zhang P, Liu B. The lipopolysaccharide Parkinson's disease animal model: mechanistic studies and drug discovery. Fund Clin Pharmacol. 2008; 22:453-64.

7. Gao HM, Liu B, Zhang WQ, Hong JS. Novel anti-inflammatory therapy for Parkinson's disease. Trends Pharmacol Sci. 2003;24:395-401.

8. Qian L, Flood PM, Hong JS. Neuroinflammation is a key player in Parkinson's disease and a prime target for therapy. J Neural Transm. 2010;117:971-9.

9. He Q, Wang Q, Yuan C, Wang Y. Downregulation of miR-7116-5p in microglia by MPP(+) sensitizes TNF-alpha production to induce dopaminergic neuron damage. Glia. 2017;65:1251-63.

10. Wichmann T, DeLong MR. Pathophysiology of Parkinson's disease: the MPTP primate model of the human disorder. Parkinson's Disease: The Life Cycle of the Dopamine Neuron. 2003;991:199-213.

11. Smeyne RJ, Jackson-Lewis V. The MPTP model of Parkinson's disease. Brain Res Mol Brain Res. 2005;134:57-66.

12. Schober A. Classic toxin-induced animal models of Parkinson's disease: 6OHDA and MPTP. Cell Tissue Res. 2004:318:215-24.

13. Ponomarev ED, Veremeyko T, Barteneva N, Krichevsky AM, Weiner HL. MicroRNA124 promotes microglia quiescence and suppresses EAE by deactivating macrophages via the C/EBP-alpha-PU.1 pathway. Nat Med. 2011;17:64-70.

14. Yang Z, Zhong L, Xian R, Yuan B. MicroRNA-223 regulates inflammation and brain injury via feedback to NLRP3 inflammasome after intracerebral hemorrhage. Mol Immunol. 2015;65:267-76.

15. Parisi C, Arisi I, D'Ambrosi N, Storti AE, Brandi R, D'Onofrio M, Volonte C. Dysregulated microRNAs in amyotrophic lateral sclerosis microglia modulate genes linked to neuroinflammation. Cell Death Dis. 2013:4:e959.

16. Cuellar TL, Davis TH, Nelson PT, Loeb GB, Harfe BD, Ullian E, McManus MT. Dicer loss in striatal neurons produces behavioral and neuroanatomical phenotypes in the absence of neurodegeneration. Proc Natl Acad Sci U S A. 2008:105:5614-9.

17. Shin D, Shin JY, McManus MT, Ptacek LJ, Fu YH. Dicer ablation in oligodendrocytes provokes neuronal impairment in mice. Ann Neurol. 2009; 66:843-57.

18. Tarallo V, Hirano Y, Gelfand BD, Dridi S, Kerur N, Kim Y, Cho WG, Kaneko H, Fowler BJ, Bogdanovich S, et al. DICER1 loss and Alu RNA induce agerelated macular degeneration via the NLRP3 inflammasome and MyD88. Cell. 2012;149:847-59.

19. Shao W, Zhang SZ, Tang M, Zhang XH, Zhou Z, Yin YQ, Zhou QB, Huang YY,

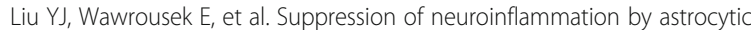
dopamine D2 receptors via alpha B-crystallin. Nature. 2013;494:90-4.

20. Tai Y, Feng S, Ge R, Du W, Zhang X, He Z, Wang Y. TRPC6 channels promote dendritic growth via the CaMKIV-CREB pathway. J Cell Sci. 2008;121:2301-7.

21. Ding C, Chan DW, Liu W, Liu M, Li D, Song L, Li C, Jin J, Malovannaya A, Jung SY, et al. Proteome-wide profiling of activated transcription factors with a concatenated tandem array of transcription factor response elements. Proc Natl Acad Sci U S A. 2013;110:6771-6.

22. Blasi E, Barluzzi R, Bocchini V, Mazzolla R, Bistoni F. Immortalization of murine microglial cells by a $v$-raf/v-myc carrying retrovirus. J Neuroimmunol. 1990;27:229-37.
23. Elgheznawy A, Shi L, Hu J, Wittig I, Laban H, Pircher J, Mann A, Provost P, Randriamboavonjy V, Fleming I. Dicer cleavage by calpain determines platelet microRNA levels and function in diabetes. Circ Res. 2015;117:157-65.

24. Lugli G, Larson J, Martone ME, Jones Y, Smalheiser NR. Dicer and elF2C are enriched at postsynaptic densities in adult mouse brain and are modified by neuronal activity in a calpain-dependent manner. J Neurochem. 2005;94: 896-905.

25. Nakagawa A, Shi Y, Kage-Nakadai E, Mitani S, Xue D. Caspase-dependent conversion of Dicer ribonuclease into a death-promoting deoxyribonuclease. Science. 2010;328:327-34.

26. Casey Klockow L, Sharifi HJ, Wen X, Flagg M, Furuya AK, Nekorchuk M, de Noronha CM. The HIV-1 protein Vpr targets the endoribonuclease Dicer for proteasomal degradation to boost macrophage infection. Virology. 2013; 444:191-202.

27. Zhang Z, Convertini $P$, Shen $M, X u X$, Lemoine $F$, de la Grange $P$, Andres DA, Stamm S. Valproic acid causes proteasomal degradation of DICER and influences miRNA expression. PLoS One. 2013;8:e82895.

28. Neumar RW, Xu YA, Gada H, Guttmann RP, Siman R. Cross-talk between calpain and caspase proteolytic systems during neuronal apoptosis. J Biol Chem. 2003;278:14162-7.

29. Hunter T. The age of crosstalk: phosphorylation, ubiquitination, and beyond. Mol Cell. 2007;28:730-8.

30. Xue Y, Ren J, Gao X, Jin C, Wen L, Yao X. GPS 2.0, a tool to predict kinasespecific phosphorylation sites in hierarchy. Mol Cell Proteomics. 2008;7: 1598-608.

31. Cross AK, Woodroofe MN. Immunoregulation of microglial functional properties. Microsc Res Tech. 2001;54:10-7.

32. Devasthanam AS, Tomasi TB. Dicer in immune cell development and function. Immunol Investig. 2014;43:182-95.

33. Kanellopoulou C, Muljo SA, Kung AL, Ganesan S, Drapkin R, Jenuwein T, Livingston DM, Rajewsky K. Dicer-deficient mouse embryonic stem cells are defective in differentiation and centromeric silencing. Genes Dev. 2005;19:489-501.

34. Bernstein E, Kim SY, Carmell MA, Murchison EP, Alcorn H, Li MZ, Mills AA, Elledge SJ, Anderson KV, Hannon GJ. Dicer is essential for mouse development. Nat Genet. 2003;35:287.

35. Klase Z, Kale P, Winograd R, Gupta MV, Heydarian M, Berro R, McCaffrey T, Kashanchi F. HIV-1 TAR element is processed by Dicer to yield a viral micro-RNA involved in chromatin remodeling of the viral LTR. BMC Mol Biol. 2007:8:63.

36. Pepin G, Perron MP, Provost P. Regulation of human Dicer by the resident ER membrane protein CLIMP-63. Nucleic Acids Res. 2012;40:11603-17.

37. Gross TJ, Powers LS, Boudreau RL, Brink B, Reisetter A, Goel K, Gerke AK, Hassan IH, Monick MM. A microRNA processing defect in smokers' macrophages is linked to SUMOylation of the endonuclease DICER. J Biol Chem. 2014:289:12823-34.

38. Drake M, Furuta T, Suen KM, Gonzalez G, Liu B, Kalia A, Ladbury JE, Fire AZ, Skeath $J B$, Arur S. A requirement for ERK-dependent Dicer phosphorylation in coordinating oocyte-to-embryo transition in C. elegans. Dev Cell. 2014;31:614-28.

39. Wang J, Lu R, Yang J, Li H, He Z, Jing N, Wang X, Wang Y. TRPC6 specifically interacts with APP to inhibit its cleavage by gamma-secretase and reduce Abeta production. Nat Commun. 2015;6:8876.

40. Bellone $\mathrm{C}$, Luscher $\mathrm{C}$. Cocaine triggered AMPA receptor redistribution is reversed in vivo by mGluR-dependent long-term depression. Nat Neurosci. 2006;9:636-41.

41. Shukla V, Zheng YL, Mishra SK, Amin ND, Steiner J, Grant P, Kesavapany S, Pant HC. A truncated peptide from p35, a Cdk5 activator, prevents Alzheimer's disease phenotypes in model mice. FASEB J. 2013;27:174-86.

42. Saporito MS, Thomas BA, Scott RW. MPTP activates C-Jun NH2-terminal kinase (JNK) and its upstream regulatory kinase MKK4 in nigrostriatal neurons in vivo. J Neurochem. 2000:75:1200-8.

43. Zhuang ZY, Wen YR, Zhang DR, Borsello T, Bonny C, Strichartz GR, Decosterd I, Ji RR. A peptide c-Jun N-terminal kinase (JNK) inhibitor blocks mechanical allodynia after spinal nerve ligation: respective roles of JNK activation in primary sensory neurons and spinal astrocytes for neuropathic pain development and maintenance. J Neurosci. 2006;26:3551-60.

44. Hebert SS, Papadopoulou AS, Smith P, Galas MC, Planel E, Silahtaroglu AN, Sergeant N, Buee L, De Strooper B. Genetic ablation of Dicer in adult forebrain neurons results in abnormal tau hyperphosphorylation and neurodegeneration. Hum Mol Genet. 2010;19:3959-69.

45. Varol D, Mildner A, Blank T, Shemer A, Barashi N, Yona S, David E, BouraHalfon S, Segal-Hayoun Y, Chappell-Maor L, et al. Dicer deficiency 
differentially impacts microglia of the developing and adult brain. Immunity. 2017:46:1030-44. e1038

46. Kaneko H, Dridi S, Tarallo V, Gelfand BD, Fowler BJ, Cho WG, Kleinman ME, Ponicsan SL, Hauswirth WW, Chiodo VA, et al. DICER1 deficit induces Alu RNA toxicity in age-related macular degeneration. Nature. 2011;471:325-30.

47. McGeer PL, McGeer EG. NSAIDs and Alzheimer disease: epidemiological, animal model and clinical studies. Neurobiol Aging. 2007;28:639-47.

48. Lee KW, Im JY, Woo JM, Grosso H, Kim YS, Cristovao AC, Sonsalla PK, Schuster DS, Jalbut MM, Fernandez JR, et al. Neuroprotective and antiinflammatory properties of a coffee component in the MPTP model of Parkinson's disease. Neurotherapeutics. 2013;10:143-53.

49. Lecca D, Nevin DK, Mulas G, Casu MA, Diana A, Rossi D, Sacchetti G, Carta AR. Neuroprotective and anti-inflammatory properties of a novel nonthiazolidinedione PPARgamma agonist in vitro and in MPTP-treated mice. Neuroscience. 2015:302:23-35.

50. Gao X, Chen H, Schwarzschild MA, Ascherio A. Use of ibuprofen and risk of Parkinson disease. Neurology. 2011;76:863-9.

Ready to submit your research? Choose BMC and benefit from:

- fast, convenient online submission

- thorough peer review by experienced researchers in your field

- rapid publication on acceptance

- support for research data, including large and complex data types

- gold Open Access which fosters wider collaboration and increased citations

- maximum visibility for your research: over $100 \mathrm{M}$ website views per year

At BMC, research is always in progress.

Learn more biomedcentral.com/submissions 